\title{
An Anarchy Prevention Device: a Quadcoptor
}

\author{
Sujeet Kumar Soni ${ }^{1}$, Ayush Kumar ${ }^{1}$, Vimlesh Singh ${ }^{1}$, Priyanka Bansal ${ }^{1}$ and Mohit Verma ${ }^{1,2, *}$ \\ 'Department of Electronics \& Communication Engineering, Manav Rachna International Institute of Research \& \\ Studies, Faridabad 121001, India; sujeetsoni019@gmail.com, ak991096@gmail.com, \\ vimlesh.fet@mriu.co.in, priyanka.fet@mriu.edu.in \\ ${ }^{2}$ Accendere CL Educate, New Delhi 110044, India; mohit.verma@accendere.co.in
}

\begin{abstract}
Background/objectives: In the last decade Unmanned Aerial Vehicles (UAVs) have become a topic of interest for many researchers worldwide. The current response system for suspicious activities and accidents are not observed or measured in real time; therefore, the main objective of this article is to develop an efficient drone that is able to provide the desired responses and solutions instantly. Methods/statistical analysis: A lightweight and stiff-structured quadcopter is proposed with the help of Adriano-based circuits. Several sensors are enabled in this structure that help drones perform accurately and efficiently. A drone incorporating into its design such a structure will be of immense help in emergency situations, such as providing critical medicinal assistance or when there is a need for critical medicine. A camera and proper communication system is present that captures, transmits, and receives data or commands by the concerned authorities. The designed system can intelligently analyse the situation and convey the required information to the issued by concerned authorities who are remotely based. It has also other uses; for it has a loudspeaker built into it using which necessary announcements can be made in a loud and clear manner, in order to prevent chaos of any kind in an critical situation that needs immediate resolution, such as warning people in situations of natural calamities or disasters or in war zones. Findings: This project focuses on the controlled surveillance of the desired location and proper communication to the concern authorities with the information of the situation as well as the location using a drone that incorporates this new design. The video/image clips captured by the drone are connected to, and displayed through, a remote computer that is manned by the control authorities. This way, with the help of the computer, the data transmitted of the surveillance location are also saved immediately into the computer's hard drive or other servers connected to the drone remotely. The designed UAV is either controlled by the human operators or travels automatically based on the electronic instructions and encoded, map patterns fed into the drone. Li-ion batteries are used in the drones that provide the required energy for the drone to function. This quadcopter can be deployed to survey locations where threat to human lives is perceived to be high. The said UAV can be utilised by several authorities for controlling or making an efficient response system that will function well in different situations such as riots, chaos, accidents, traffic jams, and so on. Improvements/application: The system presented here can indeed help with finding unusual objects, transporting essential items such as medicine, and so on. Apart from all of these advantages, it will enable the drone to perform what it is mainly intended for-to perform surveillance. Also, it is helpful to announcing necessary instructions in order to prevent the chaos.
\end{abstract}

Keywords: : Unmanned Aerial Vehicles (UAVs), Surveillance, Safety, Quick Delivery, Announcement

\section{Introduction}

Nowadays surveillance has become a part of our lives, especially in relation to security. It is very important to provide security, yet it must be done without invading into individual privacy. Unmanned Aerial Vehicle (UAV) is one of the tools that can work on these conditions. It is basically a flying object based on modern technology that connects it to remote locations from where it is controlled, operated, or flown by human operators through remote devoices and facilitates data/information exchange between the drone and the operators remotely

${ }^{*}$ Author for correspondence 
based. It is of two types: Autonomous Drone and RemoteControlled Drone. Autonomous drone is a smart device in which the map and program are already fed and thus it acts according to the instructions given by the algorithm itself. Remote-controlled drone is handled manually with the help of a remote. It has an inbuilt transmitter that transmits data and a receiver that receives instructions to function as desired by the controlling authorities. These types of surveillance and security systems help to prevent the uncertainties with greater accuracy and minimum manpower. It can act as a part of several safety management systems, such as fire safety system, traffic managing system, and so on. $\underline{1}$

Currently, this system is already in use by many government departments that deploy it for various purposes. The Department of Defence uses drones for investigating crowded areas, traffic police uses drone in hilly area for traffic control, and other entities such as various government bodies and research laboratories and factories use it as a watchdog to survey the surroundings and facilities of their operational locations.

These autonomous drones were designed and developed in 2010, and two years later were later brought to public knowledge in 2012. The first drone was dedicated for image-capturing. Then onwards rapid development and advancement of drone technology has been taking place that has phenomenally increased the accuracy with which the drones perform in order to receive and transmit data and images and so on.

Nowadays, several technology applications are served/ assisted by drone systems, such as attack drone (an automated weapon controlled by a larger system; it is basically fitted with a gun and an AI system with sensor to execute commands received from remote locations. Since there's no human intervention and operations, it totally eliminates or substantially reduces the possibility of human casualties or threat to life when soldiers wade into hostile territories), crowd control drone (comes in handy when there is civic unrest or riots on the streets; it can observe the level of intensity of the riots and help the monitors to decide the type and level of action needed to curb the riot), delivery drone (delivers goods based on orders), monitoring drone (monitors the designated area continuously for surveillance purposes), and photograph and video-capturing drone. Other areas where the drone is highly useful include the following: national security, public safety, environment research, accident detector, factories, or laboratories. $\frac{1-6}{-6}$ Table 1 presents information on different types of drones and their applications.

The present study focuses on UAVs designed mainly for surveillance. Such UAVs are equipped with unique and useful features, such as GSM and GPS, that can be used in various ways, such as it can detect fire or accidents and instantly massages the location to concerned departments. It can also be used to provide medical support or control public unrest and street riots; fitted with a loudspeaker, it can warn the crowd to disburse and leave or face action and also warns unsuspecting people if they are entering into a riot zone. ${ }^{-1} \underline{-12}$ Table 2 provides details on different techniques used to implement drone systems. Some of the previous achievements in this field are listed in Table 2. The information provided can easily show the enormous

Table 1. Drones and their areas of application

\begin{tabular}{|l|l|l|l|l|l|}
\hline S. No. & Author Name & Technique & Advantages & Limitation & Application area \\
\hline 1. & Daojing He et. al. $\underline{\text { W }}$ & Wi-Fi attack & $\begin{array}{l}\text { Secure environment } \\
\text { in our society }\end{array}$ & Area of cove & Data theft security \\
\hline 2. & $\begin{array}{l}\text { Parinya Suwansrikham } \\
\text { et. al. } \underline{\underline{2}}\end{array}$ & $\begin{array}{l}\text { Dynamic model, PID } \\
\text { and Euler's law } \\
\text { Functioning of } \\
\text { motor of drone }\end{array}$ & $\begin{array}{l}\text { Time synchronisation } \\
\text { is highly required in } \\
\text { term of providing } \\
\text { instruction and delay }\end{array}$ & $\begin{array}{l}\text { It is applicable for } \\
\text { every DC motor }\end{array}$ \\
\hline 3. & Jassim Al-Fadhli et. al. $\underline{3}$ & $\begin{array}{l}\text { Mapping soft option } \\
\text { onto hardware system }\end{array}$ & $\begin{array}{l}\text { Public safety and } \\
\text { video making }\end{array}$ & $\begin{array}{l}\text { High resolution camera } \\
\text { with very high cost }\end{array}$ & $\begin{array}{l}\text { It will give clear image } \\
\text { even in a dark place }\end{array}$ \\
\hline 4 & Cheonbok Park et. al. $\underline{4}$ & $\begin{array}{l}\text { Sound detection for } \\
\text { image processing }\end{array}$ & $\begin{array}{l}\text { To overcome the } \\
\text { issues related to the } \\
\text { visibility in image } \\
\text { detection }\end{array}$ & $\begin{array}{l}\text { The environment } \\
\text { should not be too noisy }\end{array}$ & Image processing \\
\hline 5 & $\begin{array}{l}\text { Ekkaphon Mingkhwan } \\
\text { et. al. } \underline{5}\end{array}$ & $\begin{array}{l}\text { Image stabilising } \\
\text { technique }\end{array}$ & $\begin{array}{l}\text { Providing smoother } \\
\text { video }\end{array}$ & $\begin{array}{l}\text { Provided image is not } \\
\text { clear }\end{array}$ & $\begin{array}{l}\text { Capturing image and } \\
\text { video }\end{array}$ \\
\hline
\end{tabular}


Table 2. Different techniques used for operating the drone systems

\begin{tabular}{|c|c|c|c|c|c|}
\hline S. No. & Author & Technique & Objective & Limitation & Application \\
\hline 1. & $\begin{array}{l}\text { Parinya Suwansrikham, } \\
\text { Phudinan Singkhamfu } \\
\text { et.al. } \underline{\text { }}\end{array}$ & $\begin{array}{l}\text { Dynamic model, } \\
\text { PID and Euler's } \\
\text { law }\end{array}$ & $\begin{array}{l}\text { Functioning of motor of } \\
\text { drone }\end{array}$ & $\begin{array}{l}\text { Time synchronisation is } \\
\text { highly required in term of } \\
\text { providing instruction and } \\
\text { delay }\end{array}$ & $\begin{array}{l}\text { It is applicable for } \\
\text { every dc motor }\end{array}$ \\
\hline 2. & $\begin{array}{l}\text { Ekkaphon Mingkhwan, } \\
\text { Weerawat Khawsuk } \\
\text { et.al. } \underline{5}\end{array}$ & $\begin{array}{l}\text { Image stabilising } \\
\text { technique }\end{array}$ & $\begin{array}{l}\text { To click image and video } \\
\text { with fixed camera over } \\
\text { drone }\end{array}$ & Not provide clear image & $\begin{array}{l}\text { Capturing image } \\
\text { and video }\end{array}$ \\
\hline 3. & $\begin{array}{l}\text { Tuton Chandra Mallick } \\
\text { et.al. } \underline{6}\end{array}$ & $\begin{array}{l}\text { GPS, root } \\
\text { locus method } \\
\text {, real view } \\
\text { implementation }\end{array}$ & $\begin{array}{l}\text { Lower risk to pilot, } \\
\text { camera operator, and } \\
\text { bystander, can flew } \\
\text { lower than helicopter } \\
\text { and nearby us }\end{array}$ & $\begin{array}{l}\text { Weather is major problem } \\
\text { for drones, it can ready } \\
\text { for fly after minutes when } \\
\text { weather is cleared }\end{array}$ & $\begin{array}{l}\text { National security, } \\
\text { public safety, } \\
\text { environmental } \\
\text { research }\end{array}$ \\
\hline 4. & $\begin{array}{l}\text { Mohammad alam } \\
\text { et.al. } \underline{ }\end{array}$ & $\begin{array}{l}\text { Traffic safety } \\
\text { protocol }\end{array}$ & $\begin{array}{l}\text { Reduce the risk of } \\
\text { vehicle accident and } \\
\text { minimise the resulting of } \\
\text { damage of unavoidable } \\
\text { accident }\end{array}$ & $\begin{array}{l}\text { It will only provide an } \\
\text { accident cases not for } \\
\text { traffic jam }\end{array}$ & $\begin{array}{l}\text { Making it } \\
\text { more sufficient, } \\
\text { sustainable, safe } \\
\text { and environmental } \\
\text { friendly, road } \\
\text { safety, car accident } \\
\text { detection }\end{array}$ \\
\hline 5. & $\begin{array}{l}\text { Jinmika Wijitdechakul } \\
\text { et.al. } \underline{8}\end{array}$ & $\begin{array}{l}\text { Image analysis, } \\
2 \mathrm{D} \text { and } 3 \mathrm{D} \text { object } \\
\text { recognition }\end{array}$ & & & $\begin{array}{l}\text { Surveillance and } \\
\text { security purpose }\end{array}$ \\
\hline 6. & $\begin{array}{l}\text { Muhammad Fadhil } \\
\text { Abdullah et.al. }{ }^{-}\end{array}$ & $\begin{array}{l}\text { Fire detection } \\
\text { according to the } \\
\text { colour space }\end{array}$ & $\begin{array}{l}\text { Overcome the risk of } \\
\text { damage during fire }\end{array}$ & $\begin{array}{l}\text { It will not work without } \\
\text { combination of image } \\
\text { processing because it not } \\
\text { only contain fire colour, its } \\
\text { contains smoke also }\end{array}$ & $\begin{array}{l}\text { In chemical factory, } \\
\text { science laboratory, } \\
\text { hilly areas }\end{array}$ \\
\hline 7. & $\begin{array}{l}\text { Chao-Chung Peng*, } \\
\text { Chao-Yung Hsu et.al. } \underline{10}\end{array}$ & $\begin{array}{l}\text { Rotational } \\
\text { motion }\end{array}$ & Flying of drone & $\begin{array}{l}\text { Can't fly continuously } \\
\text { more than } 8 \text { to } 10 \text { hours } \\
\text { without high power }\end{array}$ & $\begin{array}{l}\text { We can use it } \\
\text { as an indoor } \\
\text { and outdoor } \\
\text { application }\end{array}$ \\
\hline 8. & $\begin{array}{l}\text { KausarMukadam, } \\
\text { AishwaryaSinh et.al. } \underline{11}\end{array}$ & $\begin{array}{l}\text { Image processing } \\
\text { colour detection }\end{array}$ & $\begin{array}{l}\text { To provide right landing } \\
\text { area to drone }\end{array}$ & $\begin{array}{l}\text { It will not work for sea } \\
\text { areas because there is no } \\
\text { landing space }\end{array}$ & $\begin{array}{l}\text { Successfully } \\
\text { landing not include } \\
\text { tree, car }\end{array}$ \\
\hline 9. & $\begin{array}{l}\text { Sheng-Yao Hu,Tzuu- } \\
\text { Shaang Wey et.al. } \underline{12}\end{array}$ & $\begin{array}{l}\text { Call embedded } \\
\text { system using GPS }\end{array}$ & $\begin{array}{l}\text { To call the security staff } \\
\text { at right time }\end{array}$ & $\begin{array}{l}\text { Network problem in deep } \\
\text { areas }\end{array}$ & $\begin{array}{l}\text { Access control } \\
\text { device sending } \\
\text { message }\end{array}$ \\
\hline
\end{tabular}

amount of research going on in the field of developing advanced-level and more effective drones.

\section{Design Consideration}

Figure 1 is a block flowchart of a drone design (FLYTECH) and illustrates the components used and the operational procedure of FLYTECH.
The following components are used to design this drone successfully. All of the components used and their usability are described briefly.

1. KK2 flight controller

2. Frame

3. Brushless DC motors and propeller

4. Electronic speed Control (ESC)

5. Battery (Li-Po $12 \mathrm{~V} 2 \mathrm{~S}, 2.5 \mathrm{~S}$ or $3 \mathrm{~S}$ ) 


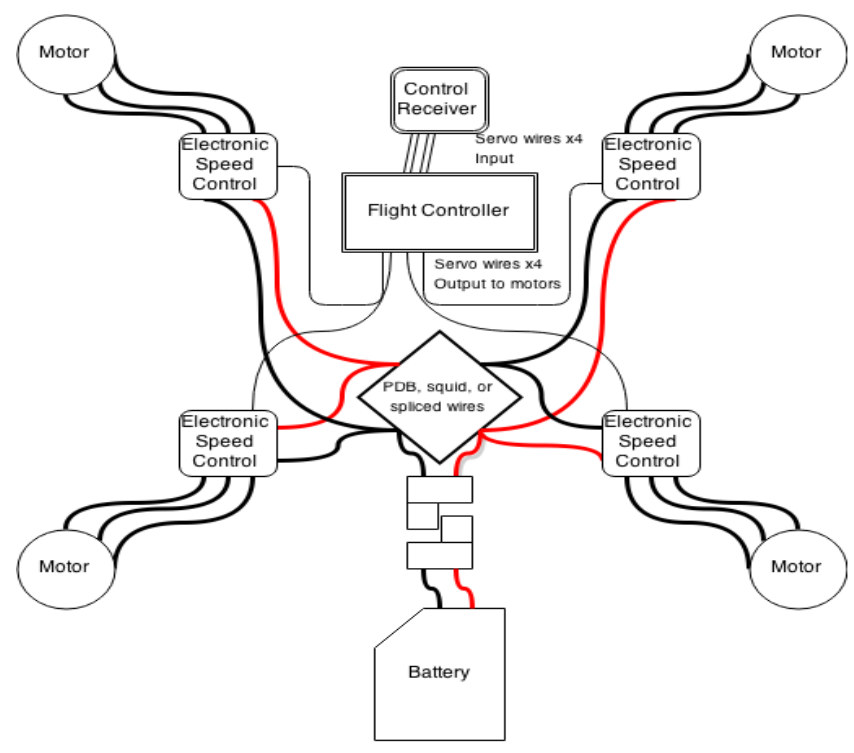

Figure 1. Model diagram of drone.

KK2 Flight controller: The main controller board used to provide the overall control to the drone is KK multicontroller. A flight control board is shown in Figure 2, which is used to adjust all the motors/rotors properly and coordinates the flying and moving functions of the drone. It also helps to keep the drone stable during flight. It receives signals through its remote and commands the motors accordingly. It uses four different types of controlling mechanisms: Roll, Throttle, Yaw, and Pitch, as shown in Figure 3 illustrating the motor functioning system.

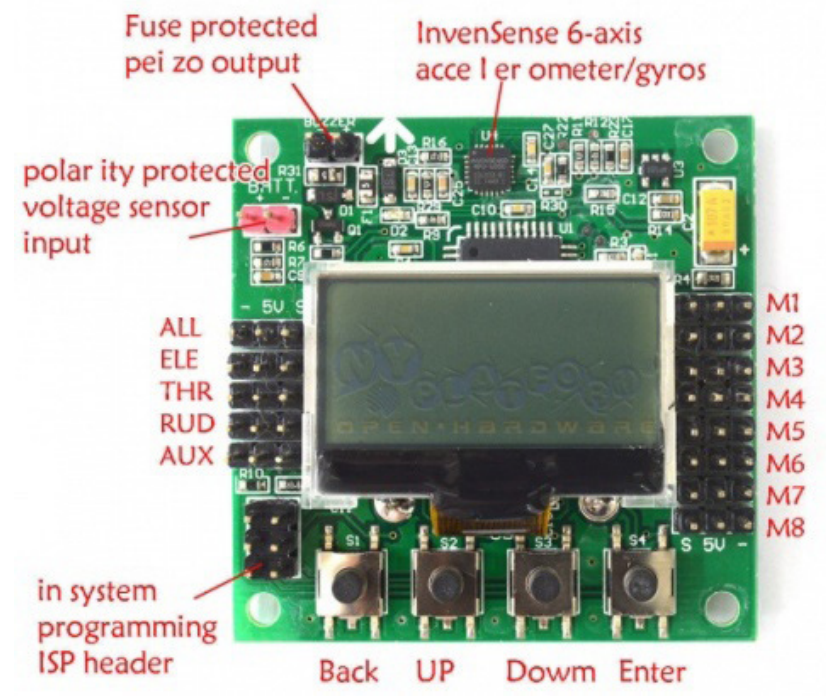

Figure 2. Flight controller module.

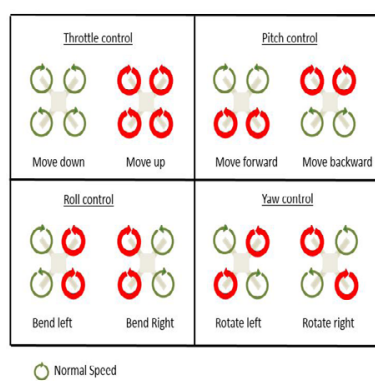

(a)

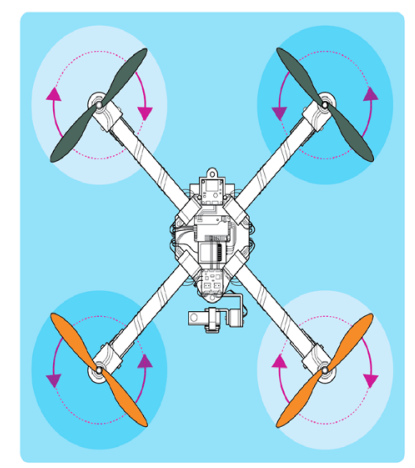

(b)
Figure 3. (a) Functionality to control drone and (b) functioning of motor.

Roll: This instruction is mainly used in order to bend and tilt the drone in required direction, that is, either left or right.

Throttle: This command is used to control the upward and downward direction of the drone. This process is done with the help of rotors. By varying the overall speed of the rotors, the drone is lifted up and/or down.

Yaw: This command is used to rotate the drone. The quadcopter rotates by speeding up all of its rotors, spinning in a single direction and slowing down all of the rotors spinning in the opposite direction. If there is a situation when it is necessary to capture the image located at the sidewise direction, this command helps to rotate the drone in the desired direction to capture images.

Pitch: This instruction is used to moving the quadcopter forward and backward. This command makes the drone works in the same way that a roll command does.

Frame: The frame is defined as the basic structure of the quadcopter. It looks like a cross symbol; it is made of various lightweight plastic materials such as carbon fibre, glass fibre, and so on. All the functional components are placed on the top of the frame and joined with each other (see Figure 3(b)). The frames need to be both strong and stiff, yet be light enough to hop around in the sky with ease.

Brushless DC motor: Brushless DC motor is also known as electronically accumulated motor. It provides AC/Bidirectional electric current to drive each phase of the motor via a closed-loop controller. To define the whole functionality of the drone, it is necessary to understand the flying mechanism of the drone. Drone's functions are mainly based on two different theories: Newton's and Euler's principles. The drone has six degrees of freedom 
of movement: $\mathrm{x}, \mathrm{y}$, and $\mathrm{z}$-directions and positive and negative in each of these direction; therefore, it can fly in any required direction. Propeller is a fan with curved wings and works on the principle of rotational motion. It converts the speed of motor into thrust, and thrust is defined as the force that counterbalances the drone's weight and helps it move in the air. The power required by the drone to fly is generated by these propellers. To maintain the stability in the air, two diagonal propellers of the drone jointly revolve in the same direction and two more revolve in the opposite direction simultaneously. The undisturbed motion of the drone needs the proper combination of the all motor rotational speeds. To make an acute alignment of motors' speeds, the partial derivative is used. With the help of this mathematical technique, the error is calculated taking the direction into the account and providing the accurate value of speed to the controller.

Electronic speed control (ESC): It regulates the speed of motor by providing a constant output voltage. Brushless ESC systems basically create a tri-phase AC power output of limited voltage from an onboard DC power input that then runs brushless motors by sending a sequence of $\mathrm{AC}$ signals generated from the ESC's circuitry.

Battery: Li-Po battery provides a wide array of benefits such as long run times and higher power output. The battery used in FLYTECH is of the following specifications: 5,500 mAh, $12 \mathrm{~V}$.

The camera used in the drone doesn't usually generate high-quality images, but we can improve it by reducing the image motions and taking the following steps: (a) motion estimate of image frames and (b) removal of undesired inter-frame motions as well as any distortion that occurs due to movement.

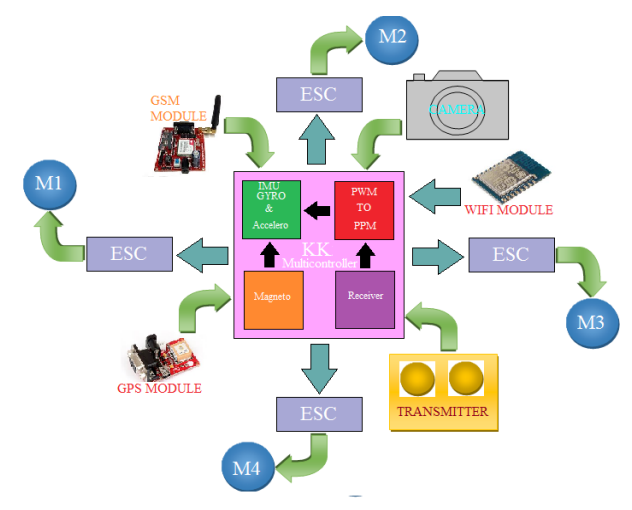

Figure 4. Drone diagram.
The designed drone is presented in Figure 4. It consists of many useful modules that serve for different applications such as safety applications, surveillance applications, and so on. The drone includes a night-vision camera for image-capturing along with GSM module and GPRS system. These modules combined provide information about the location/position and can send/ receive data/massages regarding incidents that occur in the location being monitored. It can take decisions smartly and differentiate between regular crowds and chaotic or rioting crowds efficiently.

The whole processing of this drone is based on image processing. First, an image is taken by the drone, and it is then examined by the processor according to the program encoded in it. According to the morphology of the image taken, the drones intelligently differentiate between the crowd and chaos. Then the information based on the decision is transmitted by the drone to the operators in remote locations.

As the drone moves close to the desired location, it starts capturing images along with coordinates of latitude and longitude to determine the area position. It analyses images based on various image-processing parameters, such as morphology, pixel, and so on and takes decisions regarding incidents like accidents or heavy traffic. It also captures the location with the help of GPS system that operates through instructions received from the GSM module and sends information to the control authorities operating the drone from remote locations. In typical riot situations, using the loudspeaker fitted into it and the voice file encoded into it, it can warn the crowds to disperse and leave the place peacefully.

The GSM module is operated by using AT ("attention") command. After getting instructions from GPS, the GSM initiates and sends massages in text format using command "AT+CMGF=1" and "AT+CMGS= contact no."

\section{Conclusion}

The current response system for suspicious activities and accident is not observed and reported in real time; they are captured using CCTV, but the response is not instant. It also has been observed that the image-capturing devices get damaged by hostile elements intentionally, which prevents effective and immediate action to be taken to ensure security and safety. Nevertheless, in the case of drone systems, it is very difficult to damage 
them; therefore, it will be able to carry out operations instantly, efficiently, and successfully. The present article discusses the design features of a drone that successfully performs assigned activities and informs concerned authorities about any incidents in a specific location that the drone surveys. This UAV can be used by the various departments, such as medical corps, air force, navy, police corps, and accident response departments to survey and respond instantly to resolve or tackle problems in a specific location. The major aim is to provide the solutions effectively, instantly, and help various departments to perform/operate successfully, as the current system's response time is not effective.

\section{Acknowledgement}

Authors would like to express their gratitude to the Research Mentors of Accendere Knowledge Management Services Pvt. Ltd. for their comments on an earlier version of the manuscript. Any errors still found here are only our own and should not be attributed in any way to our esteemed mentors or reviewers.

\section{References}

1. He D, Chan S, Guizani M. Drone-assisted public safety networks: the security aspect. IEEE Commun Mag. 2017;55(8):218-23.

2. Suwansrikham P, Singkhamfu P. Indoor vision based guidance system for autonomous drone and control application. In: 2017 international conference on digital arts, media and technology; 2017. P. 110-14.

3. Al-Fadhli J, Ashkanani M, Yousef A, Damaj I, El-Shafei M. RECON: a remotely controlled drone for roads safety. In: 2014 international conference on connected vehicles and expo; 2014. P. 912-8.
4. Kim J, Park C, Ahn J, Ko Y, Park J, Gallagher JC. Real-time UAV sound detection and analysis system. In: 2017 IEEE sensors applications symposium; 2017. P. 1-5.

5. Mingkhwan E, Khawsuk W. Digital image stabilization technique for fixed camera on small size drone. In: 2017 third Asian conference on defence technology; 2017. P. 12-19.

6. Mallick TC, Bhuyan MA, Munna MS. Design \& implementation of an UAV (Drone) with flight data record. In: 2016 international conference on innovations in science, engineering and technology; 2016. P. 1-6.

7. Alam M, Fernandes B, Silva L, Khan A, Ferreira J. Implementation and analysis of traffic safety protocols based on ETSI Standard. In: 2015 IEEE vehicular networking conference; 2015 . P. 143-50.

8. Wijitdechakul J, Sasaki S, Kiyoki Y, Koopipat C. UAVbased multispectral image analysis system with semantic computing for agricultural health conditions monitoring and real-time management. In: 2016 international electronics symposium; 2016. P. 459-64.

9. Abdullah MF, Wijayanto I, Rusdinar A. Position estimation and fire detection based on digital video color space for autonomous quadcopter using odroid XU4. In: 2016 international conference on control, electronics, renewable energy and communications; 2016. P. 169-73.

10. Peng CC, Hsu CY. Integration of an unmanned vehicle and its application to real-time gas detection and monitoring. In: 2015 IEEE international conference on consumer electronics-Taiwan; 2015. P. 320-21.

11. Mukadam K, Sinh A, Karani R. Detection of landing areas for unmanned aerial vehicles. In: 2016 international conference on computing communication control and automation; 2016. P. 1-5.

12. Hu SY, Wey TS, Lin MH, Hu NT. A simplified design of the embedded e-call system using GPS. In: 2011 second international conference on innovations in bio-inspired computing and applications; 2011. P. 237-40. 